НУРНАЛИСТИКА И СВЯЗИ С ОБЩЕСТВЕННОСТЬЮ

-

УДК 811.161 .1

DOI 10.18413/2712-7451-2020-39-3-321-330

\title{
«Публицист правдистской выучки»: творческая манера В.В. Овчинникова
}

Гасанова Э.Х.

Белгородский государственный национальный исследовательский университет,

Россия, 308015, г. Белгород, ул. Победы, 85;

Консалтинговое агентство социального мониторинга массовых коммуникаций, Россия, 308001, г. Белгород, ул. Преображенская, д.39

E-mail: Elmira-sun2012@mail.ru

\begin{abstract}
Аннотация. Книги В.В. Овчинникова «Ветка сакуры» и «Корни дуба» благодаря яркости их языка, выразительности слога, глубине и силы мысли, считаются шедеврами отечественной публицистики. Произведения Овчинникова находятся в поле зрения исследователей, однако востребованность осмысления его творческой индивидуальности, его методологии узнавания мира, совокупности его творческих приемов и круга мировоззренческих идей пока еще не снята. В связи с этим цель исследования - дать характеристику стилистике публицистических произведений журналиста-международника. Сделан вывод о том, что главное в творчестве публициста - стремление дать читателю новые знания, мотивирующие его не только на расширение кругозора и углубление эмоционального опыта, понимание многообразия культурных контекстов и практик современного человека, но и на формирование выверенной методологии их узнавания, от которой зависят перспективы развития общества. Впервые публицистическое творчество В.В. Овчинникова подвергается исследованию с точки зрения стилистической характеристики и творческого своеобразия. В научный оборот вводится новый эмпирический материал. Результаты могут выступать базисом для д исследований в области теории и истории публицистики, быть использованы в научно-методической работе в процессе преподавания курсов по дисциплине «Выдающиеся зарубежные публицисты» и «История зарубежной журналистики».
\end{abstract}

Ключевые слова: публицистика, журналистика, компетентность, честность, уважительность, творческие приемы, ретроспекция, повтор, риторическое усиление.

Для цитирования: Гасанова Э.Х. 2020. «Публицист правдистской выучки»: творческая манера В.В. Овчинникова. Вопросы журналистики, педагогики, языкознания, 39 (3): 321-330. DOI 10.18413/2712-7451-2020-39-3-321-330

\section{"Publicist of pravdist training": creative manner of V.V. Ovchinnikov}

\author{
Elmira K. Hasanova \\ Belgorod National Research University, \\ 85 Pobeda St., Belgorod, 308015, Russia; \\ Consulting agency for social monitoring of mass communications, \\ 39 Preobrazhenskaya St, Belgorod, 308001, Russia \\ E-mail: 767095@bsu.edu.ru
}

Abstract. The focus of attention in the article is the books of V.V. Ovchinnikov's "Sakura Branch" and "Oak Roots", which are considered masterpieces of Russian journalism due to the brightness of their 
language, expressiveness of the style, depth and power of thought. The subject of reflection is the principles and creative techniques of a publicist, revealing the originality of his manner of thinking and writing. Publicistic works of Vsevolod Ovchinnikov are in the field of view of researchers [Dokuchaeva, 2012; Shcheglova, 2014; Hasanova, 2018; Gukasov, 2018], however, the demand for understanding the originality of his personality and creative individuality, his methodology for recognizing the world, the totality of his creative techniques and the range of worldview ideas has not yet been removed. The creative manner of Vsevolod Ovchinnikov reveals the main thing in the work of a publicist - the desire to give the reader new knowledge that motivates him not only to expand his horizons and deepen his emotional experience, to understand the diversity of cultural contexts and practices of modern man, but also to form a verified methodology of their recognition, on which they depend prospects for the development of society. Due to the brightness of their language, the expressiveness of the syllable, the depth and power of thought, the methodology of cognizing the culture of different peoples, the books "Sakura Branch" and "Oak Roots" are considered a masterpiece of national journalism.

Key words: publicism, journalism, competence, honesty, respectfulness, creative techniques, retrospection, repetition, rhetorical amplification.

For citation: Hasanova E.K., 2020. "Publicist of pravdist training": creative manner of V.V. Ovchinnikov. Issues in Journalism, Education, Linguistics, 39 (3): 321-330 (in Russian). DOI 10.18413/27127451-2020-39-3-321-330

\section{Введение}

Всеволод Овчинников - выдающийся советский и российский публицист, журналист-международник, один из тех, кто активно предлагает обществу чрезвычайно значимые в мировоззренческом отношении идеи, кто своим публицистическим творчеством помогает человеку развивать способность смотреть на мир другими глазами, без предвзятости и стереотипов, один из тех, кто стоит у истоков формирования особого направления в отечественной журналистике - страноведческой журналистики. С именем Всеволода Овчинникова связано не только расширение знаний о других странах и развитие важнейшей для человека идеи культуры как поля взаимодействия, диалога и уважения, но и углубление духовного и эмоционального опыта общества, в истории которого был «железный занавес» как символ тотальной закрытости и однозначной идеологической оценочности. Публицист, много лет проработавший в Китае, Японии, Великобритании, он умел «в затхлой атмосфере классово-ненавистнической международной советской журналистики» [Лепский, 2019], в условиях доминирования стилистики советской пропаганды, идеологических клише и стереотипов вести разговор с читателем о разных странах, о принятых в них обычаях и традициях простым языком, ориентированным на активное вовлечение читателей в процесс узнавания культурного многообразия мира и совместного поиска ответов на важнейшие, возникающие в этом контексте нравственные вопросы. Книги В.В. Овчинникова, выходившие многомиллионными тиражами, учили человека жить и думать, воспитывали в нем способность уважать другого - его выбор, стиль, образ жизни. Как известно, в 1985 г. за книги «Корни дуба» и «Ветка сакуры» журналист был удостоен Государственной премии СССР, а позднее Указом президента РФ награжден орденами «За заслуги перед Отечеством» III и IV степени. Этим не исчерпывается богатый список его наград.

Свой путь в профессию В.В. Овчинников начал в 1951 г. в качестве штатного сотрудника газеты «Правда», в которой он проработал 40 лет. «Ощущаю себя счастливейшим человеком, поскольку мне не стыдно ни за одну свою строчку. Я выполнил главный долг любого журналиста - помогал людям становиться зорче, мудрее, просвещеннее и добрее», - говорил В.В. Овчинников, вспоминая свой богатый и непростой опыт работы [Овчинников, 2014, с. 
4]. Как сказал о нем Ю. Жуков, это - «публицист правдистской выучки» [Жуков, 2014, с. 55], которая и лежит в основе творческой манеры журналистика и публициста.

Публицистика в современном обществе чрезвычайно востребована. Это объясняется ее уникальным потенциалом в социальном познании и преобразовании. Публицистика - «особая форма освоения мира, в которой субъектом познания является "социальный человек", а "когнитивным ключом" - "социальная оценка" как высказывание, в котором отражается не только гражданское сознание, но и активная гражданская позиция... В публицистике воплощается одна из самых выразительных возможностей человека реализовать свое право на самостоятельную разработку социальной идеи, на самостоятельную мысль и публичное ее предъявление как точку зрения, как ценностное суждение, как гражданскую позицию, как социальную заявку на обусловленное мировоззренческими установками личности будущее» [Полонский, 2008, с. 56].

В фокусе публицистического творчества В. Овчинникова - культура других народов. Его произведения наполнены искренностью и духом романтики, что делает его произведения востребованными широкой аудиторией читателей.

Существенные перемены в журналистской деятельности связаны с применением как новейших средств коммуникации, так и рыночных коммуникативных стратегий. Они призваны обеспечить гарантированные рейтинговые показатели и, как следствие, экономическое выживание и процветание медийных организаций. Стратегии, присущие постжурналистике, включают форсированную драматизацию контента как новостного и публицистического, так и художественного, в результате чего предпочтение отдается медиатекстам, имеющим драматическую эмоциональную нагрузку, а значимая информация, не имеющая признаков конфликтности, эмоциональной нагруженности, игнорируется [Короченский, 2019, с. 7]; персонализацию контента за счет создания и эксплуатации культа «медийных звезд», которыми становятся не только деятели шоу-бизнеса, но и раскрученные через СМИ политики [Pstyga, 2017, с. 125]; гедонизацию через гипертрофированное увеличение доли развлекательного медийного содержания [Короченский, 2019, c. 8]; геймификацию, использующую игровые и спектакулярные подходы; гибридизацию медиатекстов, которые приобретают смешанные характеристики журналистскопиаровских (пиарналистики) и журналистско-про-моцийных материалов, а также носят признаки инфотейнмента [Полонский, Глушкова, 2020, с. 174]. В условиях сокращения редакционных расходов на получение и проверку информации деградирует фундаментальное для журналистики требование проверки информации на истинность [Marramao, 2017, с. 210]. Распространенной является практика опубликования фейковых новостей, нередко правдоподобных внешне, но опирающихся не на факты, а на вымысел. На основе односторонней либо недостоверной информации и апелляции к эмоциям аудитории формируются медийные образы и мифы, имеющие мало общего с реальностью [Короченский, 2019 , с. 10]. На этом фоне изучение творческой манеры В.В. Овчинникова, за плечами которого богатейший опыт качественной журналистики, представляется нам не только необходимым, но и особенно значимым и перспективным в плане и научном, и социальном.

Предметом рассмотрения в статье являются принципы и творческие приёмы публициста, раскрывающие своеобразие его манеры мыслить и писать. Цель - рассмотреть особенности творческой манеры В.В. Овчинникова на примере его публицистических книг «Ветка сакуры» и «Корни дуба», которые по праву, благодаря яркости их языка, выразительности слога, глубине и силы мысли, методологии познания культуры разных народов считаются шедевром отечественной публицистики. 


\section{Творческие особенности публицистических произведений Овчинникова}

«Ветка сакуры» - книга, впервые опубликованная в журнале «Новый мир» в 1970 г., была итогом семилетних наблюдений и размышлений Всеволода Овчинников, во время работы в Японии в качестве корреспондента газеты «Правда». Книга многократно переиздавалась не только на родине, но и в Японии. Наивысшей оценкой профессионального, творческого и личностного поступка публициста стали слова о «Ветке сакуры» Константина Симонова: «Для нашего общества она такой же глоток свежего воздуха, как песни Окуджавы» [Овчинников, 2014б].

«Корни дуба» - книга, появившаяся в результате командировки публициста в Великобританию, где он работал с 1974 г. по 1978 г. Впервые опубликованная в 1980 г. в журнале «Новый мир», книга представляет собой созданный в серии очерков психологический портрет английского общества. На обложке английского издания «Корни дуба» редактор издательства «Pergamon Press» написал: «Это не просто впечатления русского об англичанах, это честная попытка глубоко разобраться в особенностях поведения. Эта книга может быть прочитана всеми британцами как содержательное исследование наших общественных институтов, нашей политической системыл» [Овчинников, 2016] (здесь и далее в цитатах курсив наш. - Г.Э.). Известный писатель Джеймс Олдридж подчеркивал в газете «The Sunday Times»: «Вот лучший комплимент, который я мог бы сделать этой книге: я часто забывал, что писал ее не англичанин. Я вчитывался в нее, чтобы побольше узнать об обществе, в котором я живу» [Овчинников, 2014б].

В основе проведенного исследования, кроме общенаучных, лежат биографический метод, который позволил выявить уникальные аспекты личной жизни публициста, повлиявшие на его творческую деятельность, а также методы лингвостилистического анализа, при помощи которых были установлены закономерности функционирования выразительных средств языка и использования стилистических приемов в публицистическом творчестве В.В. Овчинникова.

В чем же заключаются особенности творческой индивидуальности В.В. Овчинникова, своеобразие его творческой манеры как совокупности принципов и стилистических средств, которые выделяют публициста на фоне других?

Проведенный анализ текстового материала книг «Ветка сакуры» и «Корни дуба», а также корпуса высказываний Всеволода Овчинникова и данных им на протяжении многих лет биографических интервью, показал, что исходным мировоззренческим и этическим принципом, которым публицист руководствуется в своей профессиональной и творческой деятельности, является его понимание журналистики не как ремесла, требующего для достижения цели лишь умения пользоваться некоторым инструментарием, а как служения, то есть напряженного труда во благо человека и общества. Об этом он заявляет в своих многочисленных публичных выступлениях и интервью, это также обнаруживается в его публицистическом творчестве, интеллектуально и эмоционально насыщенном, «дающим человеку методологию познания разных контекстов жизни в ее культурном многообразии и инаковости» [Полонский, 2017, с. 118].

Мир чрезвычайно многогранен и многолик, проявляется во многих формах и практиках. У каждого народа свои правила, свои нравственные императивы, своя система ценностных смыслов, которые определяют его «грамматику жизни» (В. Овчинников). Так, например, японцы отвергают индивидуализм, их мораль требует: «Найди групnу, к которой бы ты принадлежал. Будь ей верен и полагайся на нее» [Овчинников, 2014б]. «Англичан убеждают, что как в спорте, так и в жизни нужно соблюдать правила, а нарушителей их - строго наказывать» [Овчинников, 2016.]. Поэтому нельзя существующую в культуре норму и традицию автоматически переносить на другой опыт жизни. Как гово- 
рит Всеволод Овчинников, «важно преодолеть привычку подходить к другому народу со своими мерками... Нельзя мерить чужую жизнь на свой ариин, нельзя опираться на привычную систему иенностей и критериев, ибо они отнюдь не универсальны, как и грамматические нормы нашего родного языка» [Овчинников, 2014б.]. В этом - творческое кредо публициста Всеволода Овчинникова.

\section{Главные принципы в творчестве публициста}

Всеволод Овчинников уверен в том, что публицисты и журналисты - это просветители, «то, что они говорят, должно делать людей зорче, мудрее, добрее, обогащать читателя» [Соловьев, 2013, с. 179], помогать ему понимать данный в разных культурных формах окружающий его мир. Нужно научиться, как говорит Всеволод Овчинников, «переходить от вопросов “как?” к вопросам “почему?”, от журналистики описательной к журналистике аналитической» [Овчинников, 2014a, с. 10].

Общественное служение - это служение истине, которая неразрывна с принципом честности. Честность - то моральное требование, которым должен отличаться человек, рассказывающий другим о том, свидетелем чего он стал. Избегать обмана и корыстных помыслов - обязательное требование деятельности журналиста, которым Всеволод Овчинников руководствуется в своей жизни и профессии. Своим читателям он всегда представляет честную, не сконструированную в соответствии с идеологическими догмами картину того, что и каким образом происходит в культуре той или иной страны и по какой причине: «Традииионная мораль не позволяет держать душу на распашку, японеи не любит оставаться один за закрытой дверью... Строгая субординачия, которая всегда напоминает человеку о подобающем месте, требует постоянно блюсти дистанцию в жизненном строю» [Овчинников, 2014б]. Публицистически оформленный призыв Всеволода Овчинникова смотреть на окружающий мир без идеологических шор востребован и в современном обществе.

Как говорит В. Овчинников, «чтобы с мнением журналиста считались, он должен быть компетентным» [Овчинников, 2011в]. Он должен обладать основательными знаниями в той области, которая становится предметом общественного обсуждения, предметом инициируемой им дискуссии. Богатый опыт жизни и работы за рубежом сформировал авторитет Всеволода Овчинникова как непревзойденного специалиста по Китаю, Японии и Великобритании. Принципом компетентности публицист всегда руководствуется в своем публицистическом творчестве. Примеры тому без труда находятся в его книгах: «Дух приветливости и доброжелательность, пронизывающий английский сервис, неотделим от взаимной вежливости тех, кто обслуживает, и тех, кого обслуживают» [Овчинников, 2016]; «Личные отношения, основанные на личном знакомстве, играют у японцев не менее важную роль, чем официильные связи» [Овчинников, 2014б].

Ключевым для В. Овчинникова является и принцип ответственности. Для него вовсе не формально звучат слова, что журналист должен помнить о своих нравственных обязательствах не только перед профессиональным сообществом, но и перед читателями и, безусловно, перед обществом в целом. Овчинников причисляет себя к поколению шестидесятников, которые «видели свою цель в том, чтобы вооружить соотечественников правильной методикой познания зарубежной действительности» [Овчинников, 2011а]. Понимание журналистом своей ответственности особенно важно, когда предметом узнавания и оценочного комментирования становится культура целого народа.

В качестве исходного в осмыслении другой культуры для Всеволода Овчинникова является принцип уважения. Публицист в своем рассказе о другом народе и оценочном комментировании его образа жизни всегда исходит из уважения достоинства человека, его прав и свобод, никогда не допуская возможности предвзятого отношения к описываемому событию или явлению. Только на основе уважения можно понять и объяснить читателю 
незнакомую страну через культуру и историю ее народа. Как сказал В. Овчинников, «на меня поездка в любое новое место оказывает большое влияние. Развивает культурную толерантность, если хотите» [Овчинников, 2011в].

\section{Стилистические особенности в творчестве Овчинникова}

Своеобразие манеры публициста мыслить отражается и в стилистике его публицистических произведений. Лингвостилистический анализ книг В.В. Овчинникова «Ветка сакуры» и «Корни дуба» показал, что в очерках всегда присутствует четко выраженное авторское «я». Автор входит в непосредственный диалог со своими читателями, артикулированно выражает собственное мнение. В ходе описания публицист может поделиться собственными воспоминаниями, опытом жизни, высказать свои соображения по данной теме, выстроить версии, предположения, выразить собственные эмоции: «На собственном опьте могу утверждать, что по уровню сервиса Лондон значительно уступает Нью-Йорку или Токио» [Овчинников, 2014б.]; “Мне довелось дважды в жизни пережить неприятные минуты на борту самолетов, совершавших вынужденную посадку вслепую. И оба раза англичан было легко узнать среди других пассажиров, причем отличались они от остальных в лучшую сторону» [Овчинников, 2016] (здесь и далее в цитатах выделено нами. - Г.Э.).

Одним из ведущих творческих приемов, к которым обращается Всеволод Овчинников, является ретроспекция, то есть «взгляд в прошлое», отсылка читателя к предшествующему опыту и исторической информации. С его помощью публицист вводит своего читателя в рассматриваемое проблемное поле, помогая ему лучше разобраться в динамике событий и восстановить их историю: «Идея выращивать жемчужины на подводных плантациях впервые пришла сыну торговца лапшой по фамилии Микимото. В 1907 году, после девятнадиати лет безуспешных опытов, ему наконеи удалось получить сферические перлы» [Овчинников 2014б]; «В то время никто, конечно, не знал о катастрофе, случившейся в верховьях Нянчу. Река эта вытекает из озера, которое лежит на горном склоне. Таких озер, образованных ледниками, в Тибете много» [Овчинников, 2016];

Формой реализации приема ретроспекции, широко используемой в публицистике Всеволода Овчинникова, является упоминание исторических имен и наименований, выступающих в качестве репрезентации определенного культурного или политикоидеологического кода: «Прошло, однако, цельх сорок лет, прежде чем на берегах Янизы в створе островка Чжундао появились строители. Грандиозный проект, о котором мечтал еще в 1919 году великий револючионер-демократ Сунь Ятсен...» [Овчинников, 2014б]; «Вскоре после походов Чингисхана в Европу его внук Хубилай, монгольский правитель Китая, в 1274 году попытался захватить Японию, но был отбит. В 1281 году Хубилай снова предпринял поход» [Овчинников, 2014а, с. 78].

Исторические справки, предыстория событий, исторические факты, которые важны для настоящего, исторические имена - благодаря этому читатели ощущают себя участниками процессов и событий, о которых повествует В. В. Овчинников.

Особенность творческой манеры Всеволода Овчинникова проявляется также в том, что в своих книгах «Ветка сакуры» и «Корни дуба» публицист практически после каждой главы (иногда и в середине) дает подборку цитат известных отечественных или зарубежных авторов по освещаемой им теме. Например, в главе «Горожанин из пригорода» из книги «Ветка сакуры» В. Овчинников рассуждает о столице Японии, перечисляет характерные черты Токио. В конце дает вырезки из произведений других авторов. Например, слова Д. Шнейдера из его путевых очерков «Япония и японцы» 1895 г.: «Токио - лабиринт без путепроводной нити. Пользоваться здесь городским транспортом - значит обрекать себя на казнь; садиться за руль - значит отправляться в бой; ходить пешком - 
значит совериать самоубийство» [Овчинников, 2014б]. Или слова Джорджа Микеша (Англия) из книги «Страна восходящей иены» (1970 г.): «Япония является страной сюрпризов. Она часто подтверждала это своей историей вплоть до самого недавнего времени» [Овчинников, 2016].

Установка на то, чтобы убедить читателя в необходимости разобраться в особенностях другой культуры, реализуется в таком приеме, к которому зачастую обращается Всеволод Овчинников, как повтор «ключевых» слов, фраз, суждений, подчеркивающий и усиливающий намерение автора. Например, «Иначе не понять, почему ультрасовременная молодежь с ее нарочитым бунтарством проявляет покорность родительской воле в выборе спутника жизни; Иначе не понять, почему японцам свойственно ставить личную преданность выме личных убеждений, что порождает неискоренимую семейственность в политическом и деловом мире; Иначе, наконеи, не понять, как могут совмещаться в японском характере совершенно противоположные черты: иеремонность и учтивость в домашней обстановке с грубостью на улице» [Овчинников, 2014б].

Для творческой манеры Всеволода Овчинникова в целом характерно риторическое усиление речи путем использования разных выразительно-стилистических средств - риторических вопросов («А может быть, Шамбала у каждого своя? Может быть, это вершина духа, раскрывающая перед человеком заветный горизонт - единое информационное поле?» [Овчинников, 2014a, с. 125]; «Неужели это те самые японские девушки, которые слывут образцом граџиозности и сдержанности, безукоризненного контроля над проявлением своих чувств?» [Овчинников, 2014б]), пословиц, общеизвестных утверждений и прецедентных выражений («туземцы начинаются с кале» [Овчинников, 2016], «не лезь в чужие дела» [Овчинников, 2014б], «загрузить печь - что выткать циветок; обжечь - что ограбить дом» [Овчинников, 2016]), метафор и сравнений («японская учтивость; подобно индийцам, молча склоняют голову к соединенным перед грудью ладоням») и др.

Назовем еще одну особенность творческой манеры Всеволода Овчинникова стремиться быть всегда понятным своей аудитории читателей, не случайно поэтому в его очерках мы находим в том числе объяснение слов и оборотов, значение которых может быть известно далеко не каждому (например, таких как «кимоно», «харакири», «рекон», «Страна Восходящего Солнцал, «гейта», «акоя», «сквоттеры» и др.).

Таким образом, творческая манера Всеволода Овчинникова обнаруживает главное в творчестве публициста - стремление дать читателю новые знания, мотивирующие его не только на расширение кругозора и углубление эмоционального опыта, на понимание многообразия культурных контекстов и практик современного человека, но и на формирование выверенной методологии их узнавания, от которой зависят перспективы развития общества.

\section{Список источников}

1. Бобков А.К. 2005. Основы творческой деятельности журналиста. Иркутск, Иркут. ун-т, 96 с.

2. Соловьев А.А. 2013. Выбор профессии. М., Коммерсант, ЭКСМО, 384 с.

3. Жуков Ю. 2014. Человек с внимательным взглядом (послесловие). В кн.: В. Овчинников. Ветка сакуры. URL: http://ichiban.narod.ru/books/vetka/37.html (дата обращения: 1.07.2020).

4. Лепский Ю. 2019. Знать и верить. Российская газета - Федеральный выпуск. Рубрика: Общество, Вып. от 8.01.2019. URL: https://rg.ru/2019/01/01/obozrevateliu-rg-vsevolodu-ovchinnikovuprisvoeno-zvanie-zasluzhennogo-zhurnalista.html (дата обращения: 8.07.2020).

5. Овчинников В.В. 2001. Автопортрет-2001. URL: http://rulibs.com/ru_zar/nonf_publicism /ovchinnikov/1/j1.html (дата обращения: 29.06.2020).

6. Овчинников В.В. 2010. Корни дуба. М., АСТ, 220 с. 
7. Овчинников В.В. 2011а. Исповедь профессионала. РГ, 14 сент., № 204 (5580). URL: https://rg.ru/2011/09/14/ovchinnikov.html (дата обращения: 30.06.2020).

8. Овчинников В.В. 2011б. Исповедь профессионала. РГ, 15 сент., № 205 (5881) URL: https://rg.ru/2011/09/15/ovchinnikov.html (дата обращения: 30.06.2020).

9. Овчинников В.В. 2011в. Исповедь профессионала. РГ, 16 сент., № 206 (5882) URL: https://rg.ru/2011/09/16/ovchinnikov3.html (дата обращения: 30.06.2020).

10. Овчинников В.В. 2014а. Ветка сакуры. Рассказ о том, что за люди японцы. М., Молодая гвардия. $221 \mathrm{c.}$

11. Овчинников В.В. 2014б. Ветка сакуры. URL: https://online-knigi.com/page/21312 (дата обращения: 30.06.2020).

12. Овчинников В.В. 2016. Корни дуба. URL: http://booksonline.com.ua /view.php?book=135332 (дата обращения: 30.06.2020).

\section{Список литературы}

1. Антонов-Овсеенко А.А. 2019. Актуальные проблемы журналистики, медиакритики и медиаобразования. В кн.: Сборник трудов международной научно-практической конференции, Белгород 02-04 октября 2019 г. Под ред. А.В. Полонского, С.В. Ушаковой, С.М. Нарожней. ПОЛИТЕРРА: $7 \mathrm{c}$.

2. Гасанова Э.Х. 2018. Публицистическое творчество В.В. Овчинникова: тематическое своеобразие и творческие приемы. Выпуск. квалификац. работа на соискание академической степени «магистр». Белгород, 75 с. URL: https://nauchkor.ru/uploads/documents /5c1a58e27966e104f6f853f7.pdf (дата обращения: 11.07.2020).

3. Гукасова М.М. 2018. Комбинированная моносистемная персонализация на примере публицистики Всеволода Овчинникова. Политическая лингвистика, 2 (68): 45-54.

4. Докучаева И. 2012. Сравнительный анализ образа Японии в творчестве В.В. Овчинникова и В.Я. Цветова: на примере произведений "Ветка сакуры" и "Пятнадцатый камень сада Реандзи". Научные ведомости БелГУ. Серия: Гуманитарные науки, 24 (143), вып. 16: 137-140.

5. Короченский А.П. 2019. Постжурналистика: сущность, признаки, социальные эффекты. Журнал Белорусского государственного университета. Журналистика. Педагогика, 1: 6-12.

6. Нарожняя С.М. 2017. О приемах создания публицистичности в текстах отечественной литературы XI-XVII вв. В кн. Печать и слово Санкт-Петербурга. Петербургские чтения - 2016. Под ред. Т.П. Вязовик, М.Д. Кузьминой. В 2-х ч. Ч. 2: Литературоведение. Лингвистика. СПб., СПбГУПТД: 347-354.

7. Полонский А.В. 2008. Публицистика как особый вид творческой деятельности. Научные ведомости Белгородского государственного университета. Серия: Гуманитарные науки, 11 (1): $56-61$.

8. Полонский А.В. 2017. Публицистика в диалоге с жизнью. В кн. Проблемы лингвистики и лингводидактики. Вып. V. Под ред. С.А. Моисеевой, Л.Г. Петровой. Белгород, 117-121.

9. Полонский А.В., Глушкова В.Г. 2020. Современные СМИ и проблема интолерантности. Актуальные вопросы современной филологии и журналистики, 1 (36): 171-181.

10.Суздальцева В.Н. 2011. Исторические наименования как компоненты культурного кода и как имиджевый конструкт. Вестник Московского университета. Серия 10: Журналистика, 3, 143-154.

11.Тузова-Щекина С.М. 2011. Судьбы русской публицистики: художественная или массмедийная коммуникация. В кн. Средства массовой информации в современном мире. Петербургские чтения. Материалы 50-й международной научной конференции, г. Санет-Петербург, 21-22 апреля, 2011 года. Под ред. С. Г. Корконосенко. СПб., Филологический ф-т СПбГУ: 177-179.

12.Щеглова Е.А. 2014. Стилистические особенности авторской колонки «Час с Овчинниковым». Медиалингвистика. Вып. Речевые жанры в массмедиа, 53: 172-175. 
13.Beckett Ch. 2018. The paradox of power for journalism today. Medium. Available at: https://medium.com/@CharlieBeckett/the-paradox-of-power-for-journalism-today-22d33691efeb (accessed: 10.07.2020).

14. Marramao G., Casalini B. 2017. Intolleranza zero: I testi fondativi della cultura della tolleranza. Firenze, goWare, 210 p.

15.Pstyga A. 2017. Rzeczywistość medialna i medialny punkt widzenia na przekład. Międzyjezykowe I międzykulturowe konteksty współczesnego dyskursu publicznego. Gdańsk, WUG: 125-142.

\section{References}

1. Antonov-Ovseenko A.A. 2019. Aktual'nye problemy zhurnalistiki, mediakritiki i mediaobrazovanija [Actual problems of journalism, media criticism and media education]. In: Proceedings Of the international scientific and practical conference, Belgorod 02-04 October 2019. Under the editorship of A. V. Polonsky, S. V., Ushakova, S. M. Narozny. POLITERRA: 7.

2. Gasanova E.Kh. 2018. Publitsisticheskoe tvorchestvo V.V. Ovchinnikova: tematicheskoe svoeobra-zie i tvorcheskie priemy [Publicistic work of V.V. Ovchinnikova: thematic originality and creative techniques]. Release. qualification work for the academic degree "master". Belgorod, 75 p. Available at: https://nauchkor.ru/uploads/documents/5c1a58e27966e104f6f853f7.pdf (accessed: 11.07.2020).

3. Gukasova M.M. 2018. Kombinirovannaya monosistemnaya personalizatsiya na primere publitsistiki Vsevoloda Ovchinnikova [Combined monosystem personalization on the example of journalism by Vsevolod Ovchinnikov]. Political Linguistics, 2 (68): 45-54.

4. Dokuchaeva I. 2012. Sravnitel'nyy analiz obraza Yaponii v tvorchestve V.V. Ovchinnikova i V.Ya. Tsvetova: na primere proizvedeniy "Vetka sakury" i "Pyatnadtsatyy kamen' sada Reandzi" [Comparative analysis of the image of Japan in the works of V.V. Ovchinnikov and V. Ya. Tsvetova: on the example of the works "The Sakura Branch" and "The Fifteenth Stone of the Reanji Garden"]. Scientific bulletin of Belgorod State University. Humanities Sciences, 24 (143), Iss.16: 137-140.

5. Korochenskiy A.P. 2019. Postzhurnalistika: sushchnost', priznaki, sotsial'nye effekty [Postjournalism: essence, features, social effects]. Journal of the Belarusian State University. Journalism and Pedagogic, 1: 6-12.

6. Narozhnyaya S. M. 2017. O priemakh sozdaniya publitsistichnosti v tekstakh otechestvennoy litera-tury XI-XVII vv. [About the methods of creating journalism in the texts of Russian literature of the XI--XVII centuries]. In: Pechat' i slovo Sankt-Peterburga. Peterburgskie chteniya - 2016 [Seal and word of St. Petersburg. Petersburg Readings - 2016]. Sb. nauch. tr. Eds. T.P. Vyazovik, M.D. Kuz'mina. V 2-kh ch. Ch. 2: Literaturovedenie. Lingvistika [Literary criticism. Linguistics]. SPb., SPbGUPTD: 347-354.

7. Polonskiy A.V. 2008. Publitsistika kak osobyy vid tvorcheskoy deyatel'nosti [Journalism as a special kind of creative activity]. Scientific bulletin of Belgorod State University. Humanities Sciences, 11 (1): 56-61.

8. Polonskiy A.V. 2017. Publitsistika v dialoge s zhizn'yu [Journalism in dialogue with life]. In: Problemy lingvistiki i lingvodidaktiki. Mezhdunar. sb. nauch. st., NIU BelGU [Problems of linguistics and linguodidactics]. Iss.V. Eds. S.A. Moiseeva, L.G. Petrova. Belgorod, 117-121.

9. Polonskiy A.V., Glushkova V.G. 2020. Sovremennye SMI i problema into-lerantnosti [Modern media and the problem of intolerance]. Actual Issues of Modern Philology and Journalism, 1 (36): 171-181.

10. Suzdal'tseva V.N. 2011. Istoricheskie naimenovaniya kak komponenty kul'-turnogo koda i kak imidzhevyy konstrukt [Historical names as components of the cultural code and as an image construct]. The journal Vestnik Moskovskogo universiteta. Seriya 10. Zhurnalistika, 3, 143-154.

11. Tuzova-Shchekina S.M. 2011. Sud'by russkoy publitsistiki: khudozhestvennaya ili massmediynaya kommunikatsiya [The fate of Russian journalism: artistic or mass media communication]. In: Sredstva massovoy informatsii v sovremennom mire. Peterburgskie chteniya [Mass media in the modern world. Petersburg readings.]. Proceedings of the 50th international scientific conference, SaNetPetersburg, April 21-22, 2011. Ed. S.G. Korkonosenko. SPb., Filologi-cheskiy f-t SPbGU: 177-179. 
12. Shcheglova E.A. 2014. Stilisticheskie osobennosti avtorskoy kolonki «Chas s Ovchinnikovym» [Stylistic features of the author's column "Hour with Ovchinnikov"]. Media Linguistics. Iss. Rechevye zhanry v massmedia [Speech genres in mass media], 53: 172-175.

13. Beckett Ch. 2018. The paradox of power for journalism today. Medium. Available at: https://medium.com/@CharlieBeckett/the-paradox-of-power-for-journalism-today-22d33691efeb （accessed: 10.07.2020).

14. Marramao G., Casalini B. 2017. Intolleranza zero: I testi fondativi della cultura della tolleranza. Firenze, goWare, $210 \mathrm{p}$.

15. Pstyga A. 2017. Rzeczywistość medialna i medialny punkt widzenia na przekład. Międzyjezykowe I międzykulturowe konteksty współczesnego dyskursu publicznego. Gdańsk, WUG: 125-142.

\section{ИНФОРМАЦИЯ ОБ АВТОРЕ}

Гасанова Эльмира Халил кзы, аспирант кафедры журналистики института общественных наук и массовых коммуникаций Белгородского государственного национального исследовательского университета; контент-менеджер отдела развития интернетресурсов консалтингового агентства социального мониторинга и массовых коммуникаций, г. Белгород, Россия

\section{INFORMATION ABOUT THE AUTHOR}

Elmira K. Hasanova, Postgraduate Student, Department of Journalism, Institute of Social Sciences and Mass Communications, Belgorod State National Research University; Content Manager, Department of Internet Resources Development, Consulting Agency for Social Monitoring and Mass Communications, Belgorod, Russia 